\title{
lleus due to metabolic disorders after a penetrating trauma of the leg
}

\author{
Authors: $\underline{\text { ma Dadic }}{ }^{1}$, Amel Dzanic $^{1}$, Alma Kubat ${ }^{1}$, Sumeja Bandic ${ }^{1}$, Adi Mulabdic ${ }^{2}$ (mentor) \\ ${ }^{1}$ Faculty of Medicine, University of Sarajevo \\ ${ }^{2}$ University Clinical Centre of Sarajevo, Department of General and Abdominal Surgery \\ DOI: https://doi.org/10.26800/LV-142-supp5-32
}

\section{Background:}

lleus is a medical condition where a partial or full blockage of the bowel is present. It can be caused by conditions like obstruction, GI infections, electrolyte imbalances, kidney disease, medication, hernias and adhesions.

\section{Case presentation:}

4 days after surgery to repair damage of vascular structures (AFS,AP,ADP) caused by a GSW of the leg and no other injuries, a 32 y/o male patient started experiencing abdominal pain. Lab results show severe azotemia probably due to rhabdomyolysis and use of garamycin, and other indicators of acute kidney failure. CT and ultrasound of the abdomen showed distension of the short bowel $(55 \mathrm{~mm})$ with air fluid levels which indicated ileus and emergency laparotomy was performed. A strangulation in the terminal ileum was identified, along with various adhesions, and resected typically. Iliocaecal anastomosis with a protective bipolar iliostoma was done. An eneterocutaneus fistula was noticed 10 days later, requiring another surgery. Three months later, the wound is healing properly, and bowel function is well established, and kidney function is within normal parameters.

\section{Conclusion:}

Rhabdomyolysis due to high grade tissue damage, may cause kidney failure leading to electolyte imbalances that can reflect on different systems, like in this case, the bowel, especially in combination with preexistant adhesions, even though the initial problem was an isolated injury of the lower extremity. Also, kidney function should be closely monitored in patients with musculosceletal injuries.

Keywords: ileus, azotemia, rhabdomyolysis, electrolyte imbalance, kidney failure 